\title{
Fetal Neurology-Lesson Learned and Future Challenges
}

\author{
${ }^{1}$ Asim Kurjak, ${ }^{1}$ Milan Stanojevic, ${ }^{3}$ Aida Salihagic-Kadic, ${ }^{2}$ Guillermo Azumendi, \\ ${ }^{1}$ Lara Spalldi, ${ }^{1}$ Berivoj Miskovic ${ }^{1}$ \\ ${ }^{1}$ Department of Obstetrics and Gynecology, Medical School University of Zagreb, Sveti Duh Hospital, Zagreb, Croatia \\ ${ }^{2}$ Centro Gutenberg Clinic, Malaga, Spain \\ ${ }^{3}$ Department of Physiology, Medical School University of Zagreb, Zagreb, Croatia
}

Correspondence: Prof Asim Kurjak, Department of Obstetrics and Gynecology, Medical School University of Zagreb, Sveti Duh Hospital, Sveti Duh 64, Zagreb, HR 10000, Croatia, Tel. +385-1-3712317, Fax.+385-1-3745534

E-mail: asim.kurjak@public.srce.hr

\begin{abstract}
Neurological failure is the most apprehension complication of pregnancy, labor and the neonatal period. The origin and outcome correlation is frequently doubtful. The arrival of four-dimensional ultrasonography (4D US) and its function to study fetal behavior patterns have initiated to offer insight into the structural and functional fetal brain development. Although many fetal behavioral studies have been conducted, it is still questionable whether the assessment of continuity from fetal to neonatal behavior could improve our ability of early detection of brain pathology. Neurological assessment of fetus in utero is extremely difficult even having such sophisticated equipment like 4D ultrasound. As it is well known that quantity of GMs is not so informative and predictive for neurological impairment, their quality should be assessed. Gestalt perception of premature GMs we are dealing with in utero and several weeks postnatally are not as predictive for the detection of neurologically abnormal fetuses or newborns as fidgety GMs. Therefore some additional parameters should be added to the prenatal neurological examination in order to improve our ability to make the distinction between normal and abnormal fetuses.
\end{abstract}

Key words: Neurobehavioral development, Fetal behavior, Fourdimensional ultrasound.

\section{INTRODUCTION}

Understanding the structure and function of the fetal nervous system has been the dream of physicians for centuries. The pioneering efforts of Ian Donald in obstetric ultrasound in the latter part of the 20th century have permitted this dream to become a reality. The initial contribution of obstetric ultrasound focused on normal and abnormal structure. Initially, anencephaly was described and followed by increasingly subtle central nervous system abnormalities such as agenesis of the corpus callosum. The current and evolving challenge for investigators in obstetric ultrasound is to have similar success with the understanding of fetal neurological function. There are many functional neurological abnormalities such as cerebral palsy (CP) whose causes are poorly understood. There are also an escalating number of results illustrating that a large presence of neurological problems, such as minimal cerebral dysfunction, schizophrenia, epilepsy or autism, upshot at least in part from prenatal neurodevelopmental problems. Clinical and epidemiological studies have revealed that $\mathrm{CP}$ most often results from prenatal rather than perinatal or postnatal causes. ${ }^{1}$ Currently, although the momentous advances in prenatal and perinatal care, there is no mean to identify or expect the development of these disorders. Therefore, the development of diagnostic strategies to avoid and condense the saddle of perinatal brain damage has turn into one of the most imperative tasks of contemporary perinatal medicine. The application of the new, advanced imaging technique such as 4-dimensional (4D) sonography, might improve our understanding of the prenatal neurodevelopmental events and possibly facilitate the development of such strategy.

\section{Structural and Functional Development of Central Nervous System (CNS)}

The development of central nervous system begins approximately at the end of gastrulation. The generation of the neuroectoderm from ectoderm during the third postconceptional week, results in formation of the neural plate. Thus, the neural epithelium of the embryo, which is a precursor of neurons and glia, is virtually the first part of organism that acquires the separate identity from other cells. ${ }^{2}$ The formation of the neural plate is succeeded by the folding of its edges and formation of a neural tube, whose further growth and reshaping results in formation of structures of CNS. According to O'Rahilly and Muller, forebrain (prosencephalon), midbrain (mesencephalon) and hindbrain (rhombencephalon) can be distinguished in the rostral portion of the unfused neural folds. ${ }^{3}$ Earlier than it is usually referred to, approximately at 22 nd postconceptional day. In the rapid succession, during the 4th postconceptional week, 
the forebrain components-diencephalon and telencephalon can be detected. Three embryonic zones, ventricular, intermediary and marginal zone (seen from ventricular to pial surface), are present in all parts of neural tube, while telencephalon contains additional two zones, subventricular and subplate zone, Ventricular zone and subventricular zone of telencephalon are the site of neurogenesis and all the future neurons and glia are born in these structures. During migration towards the pial surface they form other transitional zones before reaching their genetically predetermined final destinations. Those destinations are cortical plate or different nuclei in the brain stem, diencephalon and basal forebrain. ${ }^{1}$ One of the transitional structures, a subplate zone that is a site for transient synapses and neuronal interactions, can play a major role in the developmental plasticity following perinatal brain damage. ${ }^{4}$ Early appearance of interneuronal connections, shown in Table 1, implicates a possibility of an early functional development. However, these first synapses exist only temporarily and disappear due to the normal reorganization processes. Most embryonic zones, types of neurons and glia and early synapses, which play crucial role in certain periods of fetal brain development, eventually disappear, significantly changing structure and function of the brain. Reorganization processes include apoptosis, disappearance of redundant synapses, axonal retraction and transposition, and transformation of the neurotransmitters phenotype. ${ }^{4}$ The Table 1 shows a significant overlap of neurogenesis, migration and synaptogenesis in the embryonic and fetal life. Development of human brain is not completed at the time of delivery. In an infant born at term, characteristic cellular layers can be observed in motor, somatosensor, visual and auditory cortical areas. Although proliferation and migration are completed in a term infant, synaptogenesis and neuronal differentiation continue very intensively. ${ }^{5}$ Brainstem demonstrates high level of maturity, whereas all histogenetic processes actively persist in cerebellum. ${ }^{6}$ Therefore, only subcortical formations and the primary cortical areas are well developed in a newborn. Associative cortex, barely visible in a newborn, is scantily developed in a 6 months old infant. Postnatal formation of synapses in associative cortical areas, which intensifies between 8th month and 2nd year of life, precedes the onset of first cognitive functions, such as speech. Following the 2nd year of age, many redundant synapses are eliminated. The elimination of synapses begins very rapidly, and continues slowly until the puberty, when the same number of synapses as seen in adults is reached. ${ }^{6}$

\section{The Origin of Fetal Behavior and Fetal Motor Development Assessed by 4D US}

The first synapses appear in the spinal cord at 6 to 7 postconceptional weeks ${ }^{7}$ and in the cortical plate at 8 postconceptional weeks. ${ }^{8}$ This is the phase when the first electrical bustle and conduction of information take places. The earliest spontaneous fetal movements can be observed at 7.5 postconceptional weeks. These movements, consisting of slow flexion and extension of the fetal trunk, accompanied by the inactive displacement of arms and legs and emerging in asymmetrical sequences, have been described as 'vermicular'. ${ }^{9,10}$ They are substituted by various general movements, which consist of head, trunk and limb movements, such as 'rippling' seen at week 8, 'twitching' and 'strong twitching' at weeks 9 and 9.5, respectively, and 'floating' 'swimming' and 'jumping' at week $10 .{ }^{11}$ Isolated limb movements emerge almost simultaneously with the general movements. At the same time with the beginning of spontaneous movements, at 7.5 postconceptional weeks, the initial motor reflex activity can be detected, permitting the hypothesis to be made of the existence of the first afferent-efferent circuits. ${ }^{7}$ At that time, head tilting following perioral stimulation was noted. The primary reflex movements are immense and signify a limited number of synapses in a reflex pathway. During the 8th week of gestation, these substantial reflex movements are replaced with local movements, possibly due to an increase in the number of axodendritic synapses. Hands become susceptible at 10, 5 weeks and lower limbs start to contribute in these reflexes at around week 14. General movements are the first sign of a supraspinal control on fetal motor activity. Approximately at the 7 postconceptional weeks, the brainstem which consists of the medulla oblongata, pons and midbrain, begins to develop and mature in a caudal to rostral direction. As the medulla matures in advance of more rostral structures of brainstem, reflexive

Table 1: Dynamics of the most important progressive processes in the development of the human brain

\begin{tabular}{llll}
\hline & Beginning & Most intensive activity & Ending \\
\hline Neurogenesis & Early embryonic period (4th week) & 8th-12th week & Approx. 20 weeks \\
Migration & Simultaneously with proliferation & 18th-24th week & 38th week \\
Synaptogenesis & 6-7th week—-spinalcord & 13th-18th week, after 24th week, & \\
& 8th week-cortical plate & 8th month-2 year of postnatal life & Puberty \\
\hline
\end{tabular}


movements of the head, body and extremities, as well as breathing movements and heart rate alterations, appear in advance of other functions. ${ }^{12}$ Since the 10 th week onwards, the amount and incidence of movements increase. By 14 to 19 weeks, fetuses are highly active with the longest period between movements of only 5 to 6 minutes. In the 15 th week, 15 singular types of movement can be observed. The general body movements and isolated limb movements, retroflexion, anteflexion and rotation of the head can be seen. Also, face movements, such as mouthing, yawning, hiccups, sucking and swallowing, can be included to an ample repertoire of fetal motor activity in this stage. ${ }^{13}$ But, during the first half of pregnancy, a dynamic pattern of neuronal production and migration, as well as the immature cerebral circuits are considered too immature for cerebral involvement in the motor behavior. ${ }^{4}$ Merely at the end of this period do a quantifiable number of synapses appear in the structures preceding the cerebral cortex, perhaps forming a substrate for the first cortical electric activity, noted at week 19. ${ }^{4}$ The spinothalamic tract is established at the 20th week and myelinized by 29 weeks of gestation and the thalamocortical connections penetrate the cortical plate at 24 to 26 weeks. Evoked potentials can be detected from the cortex at the 29th week, indicating that the functional connection between periphery and cortex operates from that time onwards. ${ }^{14}$ In the second half of pregnancy, the number of general movements gradually decreases, particularly during the last ten weeks. ${ }^{15}$ Although this decrease was first explained as a result of the reduction in amniotic fluid volume, it is now believed to be a result of maturation processes in the brainstem. ${ }^{12}$ Simultaneously with the decline in the number of generalized movements, an increase in facial movements, as well as opening or closing of the jaw, swallowing and chewing, can be observed. These activities can be seen mainly in the periods of absence of general movements, and this pattern is considered to be a manifestation of the normal neurological development of the fetus. ${ }^{15}$ However, alterations not only in the number of movements, but also in their complexity, are revealed to be the result of cerebral maturation processes. It is important to point out that subunits of the brainstem remain the main regulators of all fetal behavioral patterns until delivery. ${ }^{12}$ Despite medical reports from 100 years ago and 25 years of systematic research initiated by Prechtl and colleagues, ${ }^{16-18}$ the study of prenatal behavior is still in its infancy. One of the most promising advances in the field of ultrasonography has been the new 4D US technology. Its advance has been completed in the last year giving visualizations in almost real-time. ${ }^{19-22}$ The availability of new diagnostic data has in an extraordinary way raised our knowledge about intrauterine life, substantially modifying some earlier interpretations. ${ }^{23}$ First spontaneous fetal movements can be observed with conventional two-dimensional ultrasound (2D US) around 8th gestational week, while the newly developed
4D US allows the visualization of fetal motility one week earlier (Table 2). ${ }^{24}$ General movements are the first complex fetal movement patterns observable by $2 \mathrm{D}$ US. They can be recognized from the 8 th to 9 th weeks of pregnancy (Fig. 1) and continue to be present until 16 to 20 weeks after birth. ${ }^{18}$ According to Prechtl, these are gross movements, involving the whole body. They wax and wane in intensity, force and speed, and they have a gradual beginning and end. ${ }^{13,18}$ The majority of sequences of extension and flexion of the legs and arms is complex, and may be better assessed with 4D US. ${ }^{24}$ In the literature, there is a range between the 8th and 12th weeks concerning the first appearance of limb movements. ${ }^{13,18,20,25}$ De Vries found isolated arm and leg movements at the 8th week of gestation. ${ }^{13}$ With 4D US, limb movements at the 8th to 9th weeks were found. Using 4D sonography, Kurjak et al found that from 13 gestational weeks onwards, a "goal orientation" of hand movements appears and a target point can be recognized for each hand movement. ${ }^{19}$ More limb joints are active and move simultaneously, such as extension or flexion in arm and elbow or hip and knee. The elevation of the hand, extension of the elbow joint, with a slight change in direction and rotation, can be seen simultaneously. ${ }^{26}$ The isolated limb movements seen at the 9th week are followed by the appearance of the movements in the elbow joint at 10 weeks, changes in finger position in the 11th week and by easily recognizable clenching and unclenching of the fist at the 12th to 13 th weeks. Finally, at the 13 th to 14 th weeks, isolated finger movements can be seen, as well as an increase in the activity and strength of the hand or finger movements. ${ }^{26}$ Recent investigation of fetuses in the last trimester of gestation, performed by 4D US, has discovered an even wider range of hand and face movements than was formerly explained. ${ }^{19}$ It has been also confirmed that the fetal movement patterns in the second half of pregnancy are about equal to those monitored after birth, while the list of movements in the

Table 2: Developmental sequence of fetal behavioral patterns observed by $4 \mathrm{D}$ US in the first trimester of pregnancy

\begin{tabular}{|c|c|c|c|c|c|}
\hline \multirow[b]{2}{*}{ Type of movements } & \multicolumn{5}{|c|}{ Postconceptional weeks } \\
\hline & 7 & 8 & 9 & 10 & 11 \\
\hline General movement & + & + & + & + & + \\
\hline Startle & & + & + & + & + \\
\hline Stretching & & + & + & + & + \\
\hline Isolated arm movement & & + & + & + & + \\
\hline Isolated leg movement & & + & + & + & + \\
\hline Head rotation & & & + & + & + \\
\hline Head anteflexion & & & + & + & + \\
\hline Head retroflexion & & & + & + & + \\
\hline
\end{tabular}




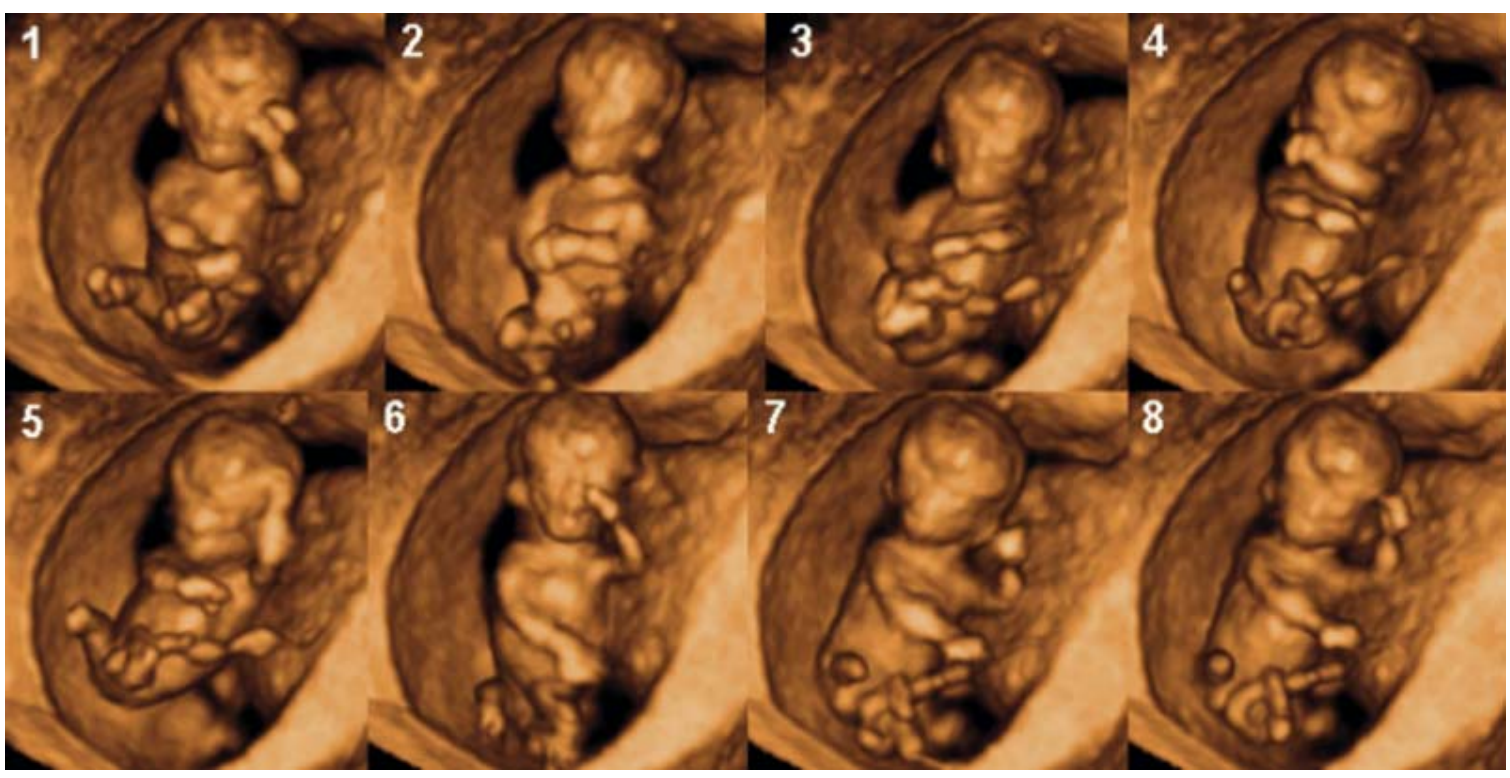

Fig. 1: 4D US imaging demonstrated fetus at 13 weeks of gestation showing general movements pattern

newborn consists of some patterns that cannot be watched in the fetus, such as the Moro reflex. ${ }^{27}$ As well, study of anencephalic fetuses have presented clear evidence for the influence of supraspinal structures on motor behavior at around the 20th gestational week. In these fetuses the number of movements was normal or even increased, but the complexity of the movement patterns distorted radically and movements were stereotyped and simplified. ${ }^{28}$

The eminence of fetal movement patterns is distorted in fetuses undergoing intrauterine growth restriction. The activities become slower and monotonous, similar to cramps and their variability in force and amplitude is reduced. ${ }^{29}$ These changes might designate the subsistence of brain lesions in growthrestricted and possibly hypoxic fetuses. Despite the premature postulations, the changes in the amplitude and complexity of movements in these fetuses do not show to be due to oligohydramnios. In cases of premature rupture of fetal membranes and a subsequently reduced volume of amniotic fluid, movements arise less frequently, but their complexity look likes that of movements achieved in the normal volume of amniotic fluid. ${ }^{16}$ Qualitative including quantitative analysis of fetal movements divulged the consistency of the fetal nervous system, and can be applied for the recognition of different cerebral dysfunctions, and probably neuromuscular ailments.

The application of the new technology, 4D US, in the examination of fetal facial movements has revealed the existence of a full range of facial expressions including grimacing, tongue expulsion and eyelid movements (Fig. 2) similar to emotional expressions in adults. ${ }^{27,30}$ The possibility of studying such subtle movements might open a new area of investigation. ${ }^{31}$
During the first trimester, a tendency towards increased frequency of fetal general movements with increasing gestational age have been noticed (Fig. 3A). While at the beginning of the second trimester, the fetuses began to display a tendency towards increased frequency of observed fetal facial expression up to the end of the second trimester. An oscillation and dispersion of the incidence of the facial expression as seen in the polynomial regression of isolated eye blinking diagram is observable in Figure 3C. ${ }^{30}$

The most frequent facial movement patterns in the second trimester were isolated eye blinking, grimacing, suckling and swallowing, while yawning, mouthing, tongue expulsion and smiling could be observed less frequently. ${ }^{25,30}$ During the third trimester, the fetuses began to display decreasing or stagnant incidence of fetal facial expression. All of the type of head movements and hand to body contact indicated a tendency to decrease frequency from the beginning of the second trimester to the end of the third trimester (Fig. 3B) ${ }^{30}$

The investigations of fetal facial expressions established that all mechanisms of the fetal yawning pattern, prolonged jaw opening followed by a quick closure and accompanied by head flexion and elevation of arms, can easily be documented by 4D US in this period (Fig. 4). ${ }^{32}$ If the fetal yawning in the third trimester was matched up to the yawning in the neonates during the first week of life, no differences were found in the frequencies of this reaction, The frequency of yawning steadily increased between 15th and 24th week when a short plateau was observed from 24th to 26th week and was followed by a slight decrease towards the term. ${ }^{30} \mathrm{~A}$ gestational age-related tendency in the frequency of yawning could be assumed as the 


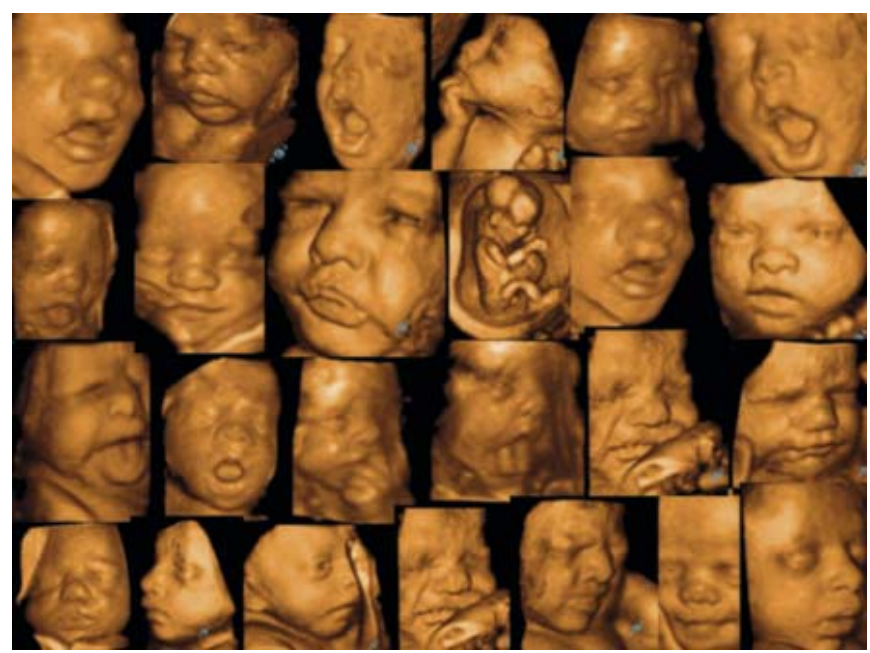

Fig. 2: 3D/4D US provides clear depiction of dynamic changes of fetal facial expression allowing study of fetal behavior during all trimesters of pregnancy

maturation of the brain stem and probably the gaining of control of more cranial structures over yawning pattern. These results have offered new data concerning the route of neurodevelopment of this fascinating, but poorly implicit reflex. Whether this is distorted in cases of neurodevelopmental disorders and whether such adaptations can give us impending into the function of fetal nervous system in high risk pregnancies, continues to be determined. It also stays to be determined to what possibility are the facial motoric patterns related to the function and integrity of the CNS. However, the fact that even in the embryonic stage, the identical inductive forces that cause growth and restyling of the neural tube influence the development of facial structures, and that many genetic disorders affecting the CNS are also described by dysmorphology and dysfunction of facial structures, underline the value of these studies. ${ }^{2,30,31}$

\section{Neonatal Aspect of Fetal Neurology}

Obstetric aspects of fetal neurology have been discussed extensively in our previous publications. ${ }^{19-25,27,28-31}$ In order to better understand fetal neurobehavioral patterns, we have learned a lot form basic studies of brain development and from clinical postnatal studies of neonates. Now, when we have reached the edge of fetal behavioral investigation by $4 \mathrm{D}$ ultrasonography in normal fetuses, we intend to find some new ideas and ways of investigation presenting neonatal aspect of fetal neurology.

Cerebral palsy (CP) is an "umbrella" term for disorders of development, movement and posture, resulting in limitations of activity due to non-progressive impairment of developing brain. ${ }^{33}$ The diagnosis of CP is retrospective and it is
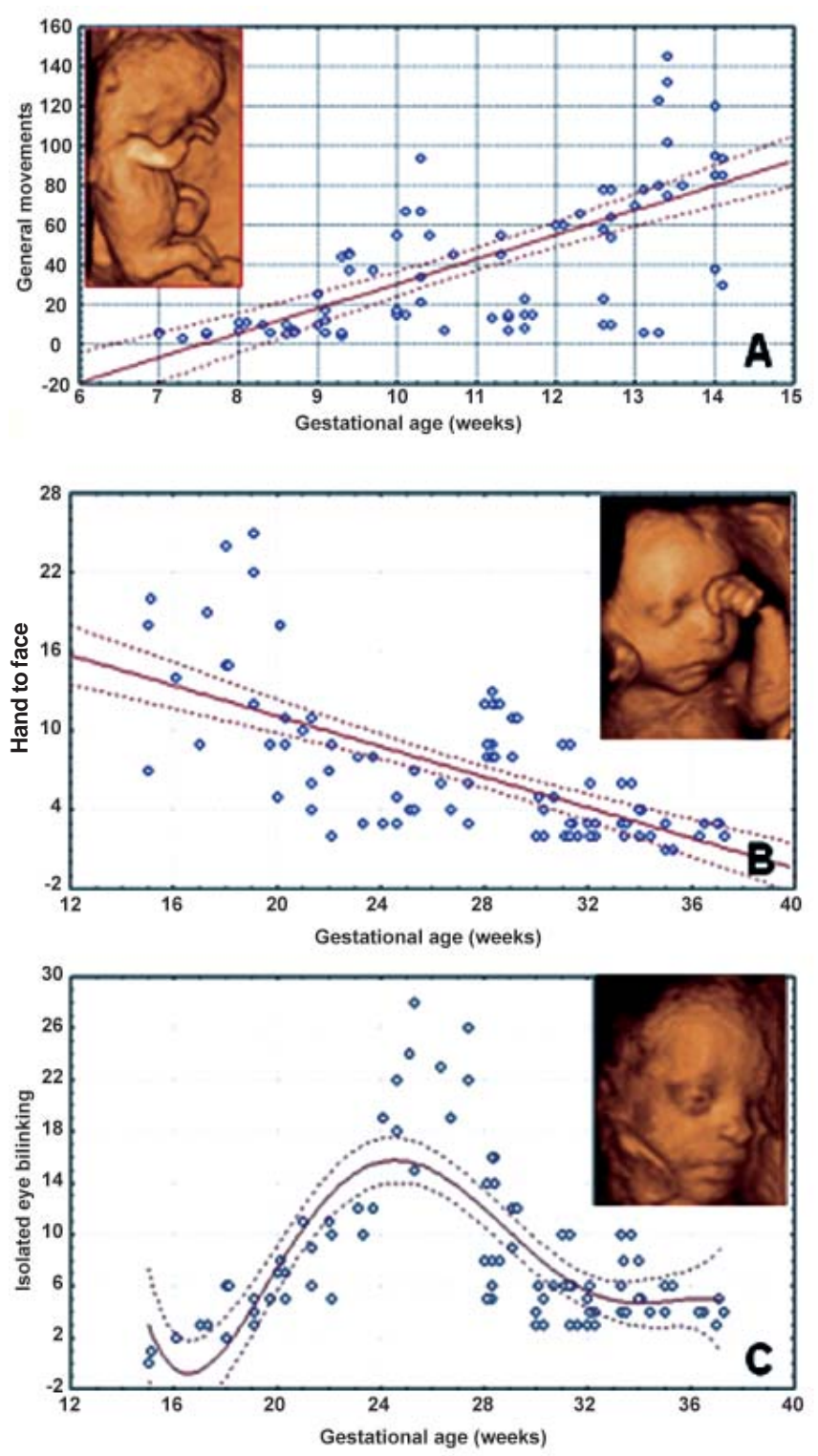

Fig. 3: Quantitative analysis of normal fetal behavior patterns using 4D-US (A) General movements; (B) Hand to face movement; (C) Isolated eye blinking

exceptionally made before the age of 6 months in only most severely affected infants, and the specificity of the diagnosis will improve as the child ages and the nature of the disability evolves. ${ }^{34} \mathrm{CP}$ does not result from a single event but rather there is a sequence of interdependent adverse events providing to the condition. ${ }^{35}$ This time frame of evolving adverse events is something which should be taken into account when considering the possibility of CP diagnosis in infants. ${ }^{34,35}$ The understanding of the profile of a child's disability across multiple domains is an ongoing process necessary for appropriate treatment and future planning. ${ }^{34}$ This theoretical statement is 


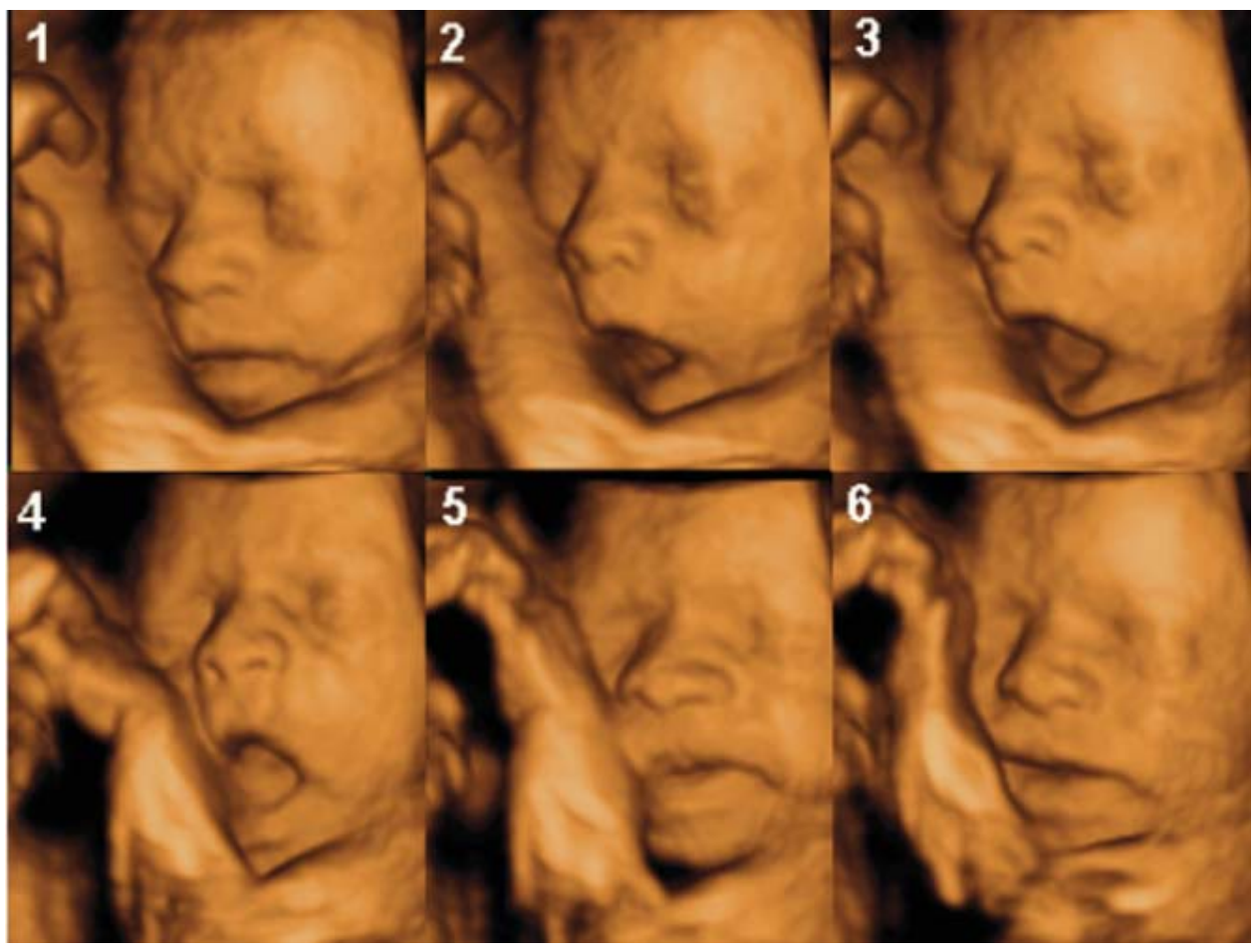

Fig. 4: 4D US image sequences of facial expression characterized by stereotyped yawning opening

sometimes very difficult to be practically implemented. An attempt to make early diagnosis of $\mathrm{CP}$ should be followed with factors related to pathogenesis, impairment and functional limitations in every patient. ${ }^{34}$ In order to identify pathogenesis of the process, neuroimaging methods should be used, among which cranial ultrasound, magnetic resonance imaging, magnetic resonance spectroscopy and diffusion weighted imaging are the most frequently used in very low birth-weight premature infants and in term infants with encephalopathy.$^{34}$ Impairment of organs or systems by clinical assessment of muscle tone, strength, and control of voluntary movements for early detection of infants with the risk for $\mathrm{CP}$ has been frustrating, because only $43 \%$ of 7-year-old children with CP had a normal newborn neurological examination. ${ }^{34,36}$ Is it possible to change this discouraging fact resulting form our failure to diagnose neurological impairment early enough to intervene? Interests in diagnosis of neurological impairment among ultrasonographers using 4D ultrasound have been recently shifted toward prenatal period. ${ }^{23,37}$ Is there any possibility to improve timing of postnatal diagnosis of neurologically disabled infant? Postnatal assessment is probably easier to perform than prenatal, by using a simple and suitable for everyday work screening clinical test with good reliability, specificity and sensitivity. Such tests are still not widely used, while those complicated and time consuming are used mostly for clinical research purposes. There is a possibility for the early and simple neurological assessment of the term and preterm newborns with the aim to detect associated risks and anticipate long-term outcome of the infant, and to establish a possible causative link between pregnancy course and neurodevelopmental outcome. ${ }^{38}$ As CP is a disorder of movement and postural control resulting in functional limitations, its diagnosis could be helpful in detection of early impairment. ${ }^{34}$ Clinical neurological assessment proposed and practiced by Amiel-Tison could be very useful in the early detection of newborns at risk. ${ }^{38}$ As development of central nervous system (CNS) is very complex and long-lasting process, the assessment of its developmental optimality is something which should be assessed in order to investigate whether the infant is neurologically normal or damaged. Neurological assessment at term by Amiel-Tison is taking into account neurological maturation exploring so called lower subcortical system developing earlier from the reticular formation, vestibular nuclei and tectum, and upper cortical system developing from the corticospinal pathways. ${ }^{39}$ The role of lower system is to maintain posture against gravity, while the upper system is responsible for the control of erect posture and for the movements of the extremities. ${ }^{39}$ At the corrected age of 40 gestational weeks optimality assessment consists of: head circumference measurement, assessment of cranial sutures, visual pursuit, social interaction, sucking reflex, raise-to-sit and reverse, passive tone in the axis, passive tone in the limbs, fingers and thumbs outside the fist, and autonomic control during assessment. ${ }^{39}$ The Amiel-Tison neurologic assessment at term is increasing accuracy in assessing CNS function in the 
neonate by using simple scoring system, focusing on the most meaningful items, promoting a clinical synthesis at term, for term and preterm infants. ${ }^{39}$ It was recognized that clinicoanatomic correlations using high resolution neuroimaging techniques could be helpful in the neurological assessment of newborns, while the neurological examination and the functional assessment of the developing CNS are bringing a new perspective of CNS status in neonatal period. ${ }^{40}$

\section{General Movements}

In the last thirty years objective assessment of videotaped general movements by Precht's method has been shown to be predictive of later $\mathrm{CP} .{ }^{9,16,18,41}$ The quality of general movements at 2 to 4 months post-term (so-called fidgety GM age) has been found to have highest predictive value in the detection of the infants at risk for CP development. ${ }^{42}$ It seems that assessment of the quality of GM is a window for early detection of children at high risk for developmental disorders. ${ }^{17,42}$ Method is simple and it is based on the so called Gestalt evaluation of GM complexity and variation. ${ }^{17,41,42}$ Assessment of GMs at 2 to 4 months post-term at so called fidgety GM age has been found to have the highest predictive value for development of $\mathrm{CP}$ if abnormal. ${ }^{17,41,42}$

Heinz Prechtl's work enabled that spontaneous motility during human development has been brought into focus of interest of many perinatologists prenatally and developmental neurologists postnatally. ${ }^{9,16,18,41,42}$ According to the research preceding Prechtl's ingenious idea, during the development of the individual the functional repertoire of the developing neural structure must meet the requirements of the organism and its environment. ${ }^{41}$ This concept of ontogenetic adaptation fits excellently to the development of human organism, which is during each developmental stage adapted to the internal and external requirements. ${ }^{41}$ Prechtl stated that spontaneous motility, as the expression of spontaneous neural activity, is a marker of brain proper or disturbed function. ${ }^{41,42}$ The observation of unstimulated fetus or infant which is the result of spontaneous behavior without sensory stimulation is the best method to assess its central nervous system capacity. ${ }^{41}$ All endogenously generated movement patterns from unstimulated central nervous system could be observed as early as from the 7 to 8 weeks of postmenstrual age, with developing a reach repertoire of movements within the next two or three weeks, continuing to be present for 5 to 6 months postnatally. ${ }^{13}$ This remarkable fact of the continuity of endogenously generated activity from prenatal to postnatal life is the great opportunity to find out those high risk fetuses and infants in whom development of neurological impairment is emerging. The most important among those movements are GMs involving the whole body in a variable sequence of arm, leg, neck and trunk movements, with gradual beginning and the end. They wax and wane in intensity, force and speed being fluent and elegant with the impression of complexity and variability. GMs are called fetal or preterm from 28 to 36 to 38 weeks of postmenstrual age, while after that we have at least two types of movements: writhing present to 46 to 52 weeks of postmenstrual age and fidgety movements present till 54 to 58 weeks of postmenstrual age. ${ }^{18,41,42}$ Lack of fluency and existence of considerable variation and complexity are the main characteristics of mildly abnormal GMs. ${ }^{43}$ When complexity, variation and fluency are absent, than we are dealing with definitely abnormal GMs. ${ }^{43}$

The quality of each individual movement includes speed, amplitude and force combined in one complex perception. ${ }^{13,18,41-44}$ Investigation of normal and neurologically impaired preterm infants showed that except for higher incidence of cloni in the abnormal group, there was no marked difference in the quantity of different motor patterns studied. ${ }^{44,45}$ However, video analysis of another group of sick preterm infants revealed a "reduction of elegance and fluency as well as variability, fluctuation in intensity and speed rather than any change in incidence of distinct motor patterns. ${ }^{44-46}$ Based on postnatal studies, it would be very important to seek for abnormal quantity and quality of prenatal movements in order to find fetuses neurologically at risk. ${ }^{46}$

Some facts are very important in the assessment of GMs. The first is that evaluation of GMs should be based on the video recorded movements either pre- or postnatally. The second fact is that when assessing GMs one should use so called "Gestalt perception", which could be described as overall impression of GMs with standardized procedure. ${ }^{41}$ During the perception one should recognize the movement patterns of GMs, than assess their complexity, variability and fluency. ${ }^{41,42}$ According to Hadders-Algra, GMs could be classified as normaloptimal, normal-suboptimal, mildly abnormal and definitely abnormal. $^{42}$ This modality of GM assessment is important for the prenatal and postnatal observation of GMs. It is not so important to assess the quantity of GMs, while the assessment of their quality is of utmost importance in terms of the prognosis of neurodevelopmental outcome. They can better predict neurodevelopmental outcome than classical neurologic examination alone. $^{47}$

We can conclude that prenatal and postnatal assessment of GMs according to Prechtl's method gives quite new insight on the function and development of central nervous system. This important modality is time consuming and requires some technology and expertise to be practiced, but advantages of its implementation in prenatal and postnatal life are very promising and encouraging in terms of its prognostic value. Prenatal assessment of GMs is well developed and established, while prenatal assessment needs sophisticated real time 4D ultrasonographic or other technology in order to enable more precise assessment of GM quality in fetuses. 


\section{Continuity of GMs from Prenatal to Postnatal Life}

Postnatal studies of neonatal behavior have taught us that the assessment of behavior is a better predictor of neurodevelopment disability than neurological examinations. ${ }^{46}$ It is important to mention that postnatal observation of movement patterns was introduced by Prechtl and coworkers in the way that they have been observing spontaneous movements of the infant using video typing and "off-line" analysis of both quantity and quality of the movement. ${ }^{17,48}$ They proved that assessment of general movements in high risk newborns has significantly higher predictive value for later neurological development than neurological examination. ${ }^{46,47,49}$ Kurjak and coworkers conducted a study by 4D ultrasound and confirmed earlier findings made by $2 \mathrm{D}$ ultrasonography, that there is behavioral pattern continuity from prenatal to postnatal life. ${ }^{27}$ Assessment of neonatal behavior is a better method for early detection of CP than neurological examination alone. ${ }^{50}$ It is being speculated that intrauterine detection of encephalopathy would improve the outcome. Although many fetal behavioral studies have been conducted, it is still questionable whether the assessment of continuity from fetal to neonatal behavior could improve our ability of early detection of brain pathology. Early detection could possibly rise an opportunity to intervene and even prevent the expected damage.

Could some postnatal signs of neurological disability be used prenatally?

It has been proven by now that ultrasonography is a powerful tool in the assessment of fetal behavior. 4D sonography brought up to light visual observation of the fetus, particularly in two especially important domains: fetal finger movements and facial expressions. ${ }^{19,51}$ This new technology is not only a toll of fetal observation but a very useful toll to evaluate the development of fetal CNS in normally developing fetuses and those at high risk. A basic understanding of fetal neurology includes: defining of motor pathways involved, chronology of their maturation and direction of myelination. ${ }^{52,53}$ This information helps clinician in better interpretation of fetal movements. The experience acquired with the Amiel-Tison's Neurological Assessment at Term (ATNAT) helps us in interpretation of fetal movements. $39,54,55$

The domain of fetal neurology is already too extensive, but the focus of interest is mainly second trimester, despite the fact that spontaneous fetal mobility emerges and has already became differentiated at a very early age. ${ }^{56}$ This means that we will take into a consideration period of pregnancy from 20 till 40 weeks of gestation, including the end of the neuronal migration and the postmigratory phase corresponding to the development of neocortex. ${ }^{4,57}$

As it was already mentioned, CP describes a group of disorders of the development of movement and posture, causing activity limitations, which are attributed to non-progressive disturbances occurring at the time of fetal brain development. ${ }^{58-61}$ Motor disorders which occur in patients with $\mathrm{CP}$ are often accompanied by disturbances of sensation, cognition, communication, perception, behavior, and/or with seizure disorder. ${ }^{58-61 ~ " D i s t u r b a n c e s " ~ i s ~ a ~ t e r m ~ t h a t ~ r e f e r s ~ t o ~ e v e n t s ~ o r ~}$ processes that in some way influence the expected pattern of brain maturation. ${ }^{55}$ Those events or processes are many, with consequences varying from very conspicuous to very subtle. It should be kept in mind what many neurologists emphasize, that morphology does not always correspond to neurological outcome. ${ }^{39,54,55}$ The opposite view is the one from pediatricians and neurophysiologists, who are involved in long-term followup studies, and they are certainly not that optimistic. It would be wise to consider long run prognosis, for each specific type of fetal brain damage and make appropriate decisions for conservative management.

Hopes have been headed towards MR, but in many cases brain changes can not be detected as early as the first year of life, like for example pathological gliosis which causes secondary hypomyelinization.

While examining the fetal head by 4D, sonographer should examine bony structures and fetal cranial sutures, if they are folding over one another, it is considered to bee a bed sign previously described by Amiel-Tison. ${ }^{39,55}$ The same sign should be searched for postnatally, as a part of neurological examination. $^{62}$

The majority of pediatricians believe that the main obstacle for early prediction of CP based on a functional observation of the fetus such as visual observation by 4-D sonography, is due to the "precompetent" stage of most of the motor behavior observed in utero. ${ }^{39,55}$ One of the possible signs detected could be high arched palate, described by Amiel-Tison, in clinical assessment of the infant nervous system. ${ }^{39,55}$ What was believed as undetectable became visible by 4D. Recently, the 3D "reverse face technique" has been described. This technique overcomes shadowing the fetal face by rotating the frontal facial image through $180^{\circ}$ along the vertical axis, so that the palate, nasal cavity and orbits become visualized. ${ }^{63,64}$

Pooh and Ogura examined 65 normal fetuses by 3D/4D. The purpose of their study was to investigate the natural course of fetal hand and finger positioning. ${ }^{26}$ During 9 th and on the beginning of 10th week fetal hands were located in front of the chest and no movements of wrists and fingers were visualized. From the middle of 10th week, active arm movements were observed. ${ }^{26}$ This study is very important, because it is showing that finger and thumbs movements begun in the early stage of human life, long before the maturation of the upper system. Therefore this motor activity depends on the lower system and not before 30-32 weeks switches to the upper control. 
Amiel-Tison also described so called neurologic thumb squeezed in a fist. Clenched fingers can also be detected by 4D sonography, as well as overlapping cerebral sutures. ${ }^{19,26}$

Head anteflexion becomes visible during 10th and 11th gestational weeks, according to de Vries and co-workers. ${ }^{56}$ However, the activity of flexor muscles will depend on the upper system since 34 weeks of gestation. The absence of active head flexion explored by the raise-to-sit maneuver is one of the major neurological signs at 40 weeks of gestation. ${ }^{39,54,62}$

\section{CONCLUSION}

Neurological assessment of fetus in utero is extremely difficult even having such sophisticated equipment like 4D ultrasound. As it is well known that quantity of GMs is not so informative and predictive for neurological impairment, their quality should be assessed. Gestalt perception of premature GMs we are dealing with in utero and several weeks postnatally are not as predictive for the detection of neurologically abnormal fetuses or newborns as fidgety GMs. ${ }^{41,43}$ Therefore some additional parameters should be added to the prenatal neurological examination in order to improve our ability to make the distinction between normal and abnormal fetuses or to assess optimality of CNS development. ${ }^{39,54,62}$ DiPietro states that an emerging consensus recognizes the fact that "fetal neurobehavioral reflects the developing nervous system", however we don't know yet the conceptual and methodological strengths and weaknesses of fetal assessments proposed. ${ }^{65}$ We are not ready yet to predict the neurological outcome in fetuses between two extreme situations, optimal or very abnormal. The predictive value for a favorable outcome of a complete neurobehavioral pattern in fetus as from 22 gestational weeks on should be demonstrated. Possibilities of 4D sonography are demonstrating the prenatal onset of a brain damage, based on morphological and functional signs. There is no doubt that this observation will be helpful, even though that prenatally observed signs are not yet highly predictive due to the brain immaturity, their identification will be at least recognized as a retrospective marker for a prenatal insult. $^{39,54,62}$

Are we approaching the era when there will be applicable neurological test for fetus and assessment of neonate will be just the continuation? This question is still not easy to answer, because even postnatally there are several neurological methods of evaluation, while in utero we are dealing with more complicated situation and less mature brain. Could neonatal assessment of neurologically impaired fetuses bring some new insights into their prenatal neurological status is still unclear and to be investigated.

\section{REFERENCES}

1. Salihagic-Kadic A, Kurjak A, Medic M, Andonotopo W, Azumendi G. New data about embryonic and fetal neurodevelopment and behaviour obtained by 3D and 4D sonography. J Perinat Med 2005;33:478-90.

2. Pomeroy SL, Voipe JJ. Development of the nervous system. In Polin RA, Fox WW (Eds): Fetal and neonatal physiology. Philadelphia-London-Toronto-Montreal-Sydney-Tokyo: WB Saunders Copmany 1992;1491-1509.

3. O'Rahilly R, Muller F. Minireview: Summary of the initial development of the human central nervous system. Teratology 1999;60:39-41.

4. Kostovic I, Judas M, Petanjek Z, Simic G. Ontogenesis of goaldirected behavior: anatomo-functional considerations. Int $\mathrm{J}$ Psychophysiol 1995;19:85-102.

5. Schaher S. Determination and differentiation in the development of the nervous system. In Kandel ER, Schwartz JH (Eds): Principles of Neural Science 2nd ed. New York: Elsevier Science Publishing 1985:730-2.

6. Kostovic I. Prenatal development of nucleus basalis complex and related fibre system in man: a histochemical study. Neuroscience 1986;17:1047-77.

7. Okado N. Onset of synapse formation in the human spinal cord. J Comp Neurol 1981;10;201:211-9.

8. Kostovic I. Zentralnervensystem. In Hinrichsen KV (Ed): Humanembryologie. Berlin: Springer-Verlag, 1990;381-448.

9. Prechtl FHR. Ultrasound studies of human fetal behaviour. Early Hum Dev 1985;2:91-8.

10. Ianniruberto A, Tajani E. Ultrasonographic study of fetal movements. Semin Perinatal 1981;4:175-81.

11. Goto S, Kato TK. Early movements are useful for estimating the gestational weeks in the first trimester of pregnancy. In Levski RA, Morley P, (Eds): Ultrasound '82. Oxford: Pergamon Press, 1983;577-82.

12. Joseph R. Fetal brain and cognitive development. Dev Rev 1999;20:81-98.

13. de Vries JIP, Visser GHA, Prechtl HFR. The emergence of fetal behavior I. Qualitative aspects. Early Hum Dev 1982;7:301-22.

14. Kostovic I, Rakic P. Development of prestriate visual projections in the monkey and human fetal cerebrum revealed by transient cholinesterase staining. J Neurosci 1984;4:25-42.

15. D'Elia A, Pighetti M, Moccia G, Santangelo N. Spontaneous motor activity in the normal fetus. Early Human Dev 2001;65:139-44.

16. Prechtl HFR, Einspieler C. Is neurological assessment of the fetus possible? Eur J Obstet Gynecol Reprod Biol 1997;75:81: 4.

17. Roodenburg PJ, Wladimiroff JW, van Es A, Prechtl HFR. Classification and quantitative aspects of fetal movements during the second half of pregnancy. Early Hum Dev 1991;25:19-35.

18. Prechtl FHR: Qualitative changes of spontaneous movements in fetus and preterm infant are a marker of neurological dysfunction. Early Hum Dev 1990;23:151-8.

19. Kurjak A, Azumendi G, Vecek N, Kupesic S, Solak M, Varga D, Chervenak F. Fetal hand movements and facial expression in normal pregnancy studied by four-dimensional sonography. J Perinat Med 2003;31:496-508.

20. Andonotopo W, Stanojevic M, Kurjak A, Azumendi G, Carrera JM. Assessment of fetal behavior and general movements by 
four-dimensional sonography. Ultrasound Rev Obstet Gynecol 2004;4:103-14.

21. Kurjak A, Stanojevic M, Azumendi G, Carrera JM. The potential of four-dimensional (4D) ultrasonography in the assessment of fetal awareness. J Perinat Med 2005;33:4653.

22. Kurjak A, Pooh RK, Carrera JM, Merce L, Salihagic-Kadic A, Andonotopo W: Structural and functional early human development assessed by three-dimensional (3D) and fourdimensional (4D) sonography. Fertil Steril 2005;84:128599.

23. Kurjak A, Miskovic B, Andonotopo W, Stanojevic M, Azumendi G, Vrcic H. How useful is 3D and 4D ultrasound in perinatal medicine. J Perinat Med 2007;35:10-27.

24. Andonotopo W, Medic M, Salihagic-Kadic A, Milenkovic D, Maiz N, Scazzocchio E. The assessment of embryonic and fetal neurodevelopment in early pregnancy: comparison between 2D and 4D sonographic scanning. J Perinat Med 2005;33:406-14.

25. Kurjak A, Stanojevic M, Andonotopo W, Scazzocchio-Duenas E, Azumendi G, Carrera JM. Fetal behavior assessed in all three trimesters of normal pregnancy by four-dimensional ultrasonography. Croat Med J 2005;46:772-80.

26. Pooh RK, Ogura T. Normal and abnormal fetal hand positioning and movement in early pregnancy detected by three- and fourdimensional ultrasound. Ultrasound Rev Obset Gynecol 2004:4:46-51.

27. Kurjak A, Stanojevic M, Andonotopo W, Salihagic-Kadic A, Azumendi G, Carrera JM. Behavioral pattern continuity from prenatal to postnatal life-a study by four-dimensional (4D) ultrasonography. J Perinat Med 2004;32:346-53.

28. Andonotopo W, Kurjak A, Kosuta MI. Behavior of anencephalic fetus studied by 4D sonography. J Matern Fetal Neonatal Med 2005; $17: 165-8$.

29. Andonopo W, Kurjak A. The assessment of fetal behavior of growth restricted fetuses by 4D sonography. J Perinat Med 2006;34:471-8.

30. Kurjak A, Andonotopo W, Hafner T, Salihagic-Kadic A, Stanojevic M, Azumendi G, Ahmed B, Carrera JM, Troyano JM. Normal standards for fetal neurobehavioural developmentslongitudinal quantification by four-dimensional sonography. $\mathrm{J}$ Perinat Med 2006;34:56-65.

31. Kurjak A, Azumendi G, Andonotopo W, Salihagic Kadic A. Three- and four-dimensional ultrasonography for the structural and functional evaluation of the fetal face. Am J Obstet Gynecol 2007;196:16-28.

32. Walusinski O, Kurjak A, Andonotopo W, Azumendi G. Fetal yawning assessed by 3D and 4D sonography. Ultrasound Rev Obstet Gynecol 2005;5:210-7.

33. Rosenbaum P, Paneth N, Leviton A, Goldstein M, Bax M, Damiano D, Dan B,Jacobsson B. A report: the definition and classification of cerebral palsy April 2006. Dev Med Child Neurol 2007;109 (suppl.):8-14.

34. Palmer FB. Strategies for the early diagnosis of cerebral palsy. J Pediatr 2004;145:S8-S11.

35. Walstab JE, Bell RJ, Reddihough DS, Brennecke SP, Bessell $\mathrm{CK}$, Beischer NA. Factors identified during the neonatal period associated with risk of cerebral palsy. Australian and New Zeland Journal of Obstetrics and Gynecology 2004;44:342-6.
36. Nelson KB, Ellenberg JH. Neonatal signs as predictors of cerebral palsy. Pediatrics 1979;64:225-32.

37. Amiel Tison C, Gosselin J, Kurjak A. Neurosonography in the seconf half of fetal life: a neonatologist point of view. J Perinat Med 2006;34:437-46.

38. Gosselin J, Gahagan S, Amiel-Tison C. The Amiel-Tison neurological assessment at term: conceptual and methodological continuity in the course of follow-up. Mental Retardation and Developmental Disabilities Research Reviews 2005;11:34-51.

39. Amiel-Tison C. Update of the Amiel-Tison Neurological assessment for the term neonate or at 40 weeks corrected age. Pediatr Neurol 2002;27:196-212.

40. Volpe JJ. Neurological examination: Normaland abnormal fetures. In Neurology of the newborn (4th edn). Philadelphia:WB Saunders, 2001:127.

41. Einspieler C, Prechtl HFR, Bos AF, Ferrari F, Cioni G. Prechtl's, ethod on the qualitative assessment of general movements in preterm, term and young infants.Mac Keith Press, Cambridge, 2004.

42. Hadders-Algra M. General movements: a window for early identification of children at high risk for developmental disorders. J Pediatr 2004;145:S12-8.

43. Hadders-Algra M, Klip-Van den Niewcendijk WJ, Martijn A, van Eyken L. Assessment of general movements: towards a better understanding of a sensitive method to evaluate brain function in young infants. Dev Med Child Neurol 1997;39:8999.

44. Bekedam DJ, Visser GHA, de Vries JJ, Prechtl HFR. Motor behaviour in the growth retarded fetus. Early Human Development 1985; 12:155-65.

45. Cioni G, Prechtl HF. Preterm and early postterm motor behaviour in low-risk premature infants. Early Hum Dev 1990;23:159-91.

46. Seme-Ciglenecki P. Predictive value of assessment of general movements for neurological development of high-risk preterm infants: comparative study. Croatian Medical Journal 2003;44:721-7.

47. Cioni G, Prechtl HFR, Ferrari F, Paolicelli PB, Einspieler C, Roversi MF. Which better predicts later outcome in full term infants: quality of general movements or neurological examination?.Early Hum Dev 1997;50:71-85.

48. Einspieler C, Prechtl HF, Ferrari F, Cioni G, Bos AF. The qualitative assessment of general movements in preterm, term and young infants-review of the methodology. Early Hum Dev 1997;24:47-60.

49. Ferrari F, Cioni G, Einspieler C, Roversi MF, Bos AF, Paolicelli PB, Ranzi A, Prechtl HF.Cramped synchronized general movements in preterm infants as an early marker for cerebral palsy. Arch Pediatr Adolesc Med 2002;156:460-7.

50. Prechtl HFR. State of the art of a new functional assessment of the young nervous system. An early predictor of cerebral palsy. Early Hum Dev 1997;50:1-11.

51. Kurjak A, Jackson D (eds.) An atlas of Three- and FourDimensional Sonography in Obstetrics and Gynecology. Taylor \& Francis Group: London, 2004.

52. Sarnat HB. Anatomic and physiologic correlates of neurologic development in prematurity. In Sarnat HB (Ed): Topics in neonatal neurology. New York: Grune and Stratton, 1984;1-24. 
53. Sarnat HB. Functions of the corticospinal and corticobulbar tracts in the human newborns. J Pediatr Neurol 2003;1:3-8.

54. Amiel-Tison C. Clinical assessment of the infant nervous system. In Levente MI, Chervenak FA and Whittle M (Eds): Fetal and Neonatal Neurology and Neurosurgery (3rd edn). Churchill Livingstone: London, 2001;99-120.

55. Salisbury AL, Duncan Fallone M, Lester B. Neurobehavioral Assessment from Fetus to Infant: the NICU Network Neurobehavioral Scale and the Fetal Neurobehavioral Coding System. MRDD Research Reviews 2005;11:14-20.

56. de Vries JIP, Visser GHA, Prechtl HFR. Fetal motility in the first half of pregnancy. In: Prechtl HFR (ed.) Continuity of neural functions from prenatal to postnatal life. Clin Dev Med 94 Oxford, Blackwell, 1984;46-63.

57. KostoviæI, Seress L, Mrzljak L, Judaš M. Early onset of synapse formation in the human hippocampus: a correlation with NisslGolgi architectonics in 15- and 16.5-week-old fetuses. Neuroscience 1989;30:105-16.

58. Mutch L, Alberman E, Hagberg B, Kodama K, Perat MV. Cerebral palsy epidemiology: where are we now and where are we going? Dev Med Child Neurol 1992;34:547-51.
59. Bax M, Goldstein M, Rosenbaum P, Leviton A, Paneth N, Dan B, Jacobsson B, Damiano D, Executive Committee for the Definition of Cerebral Palsy. Proposed definition and classification of cerebral palsy, April 2005. Dev Med Child Neurol 2005;47:571-6.

60. Sankar C, Mundkur N. Cerebral palsy-definition, classification, etiology and early diagnosis. Indian J Pediatr 2005;72:865-8.

61. Shapiro BK. Cerebral palsy: a reconceptualization of the spectrum. J Pediatr 2004;145 (Suppl. 2):S3-7.

62. Amiel-Tison C, GosselinJ, Infante-Rivard C. Head growth and cranial assessment at neurological examination in infancy. Dev Med Child Neurol 2002;44:643-8.

63. Pooh RK, Pooh K, Nakagawa Y, Nishida S, Ohno Y. Clinical application of three-dimensional ultrasound in fetal brain assessment. Croat Med J 2000;41:245-51.

64. Campbell S, Lees C, Moscoso G, Hall P. Ultrasound antenatal diagnosis of cleft palate by a new technique: the 3D "reverse face" view. Ultrasound Obstet Gynecol 2005;25:12-8.

65. DiPietro JA. Neurobehavioral assessment before birth. Mental Retardation and Developmental Disabilities Research Reviews 2005;11:4-13. 